\title{
AC 2012-5029: TROUBLESHOOTING SKILLS FOR NON-ENGINEERS IN TECHNOLOGICAL JOBS
}

\author{
Ing. Mariana Tafur, Purdue University, West Lafayette
}

Mariana Tafur has a M.S., education, Los Andes University, Bogota, Colombia; and a B.S., electrical engineering, Los Andes University, Bogota, Colombia. She is a 2010 Fulbright Fellow. Her research interests include engineering skills development, STEM for non-engineers adults, motivation in STEM to close the technology literacy gap, and STEM formative assessment.

\section{Dr. Demetra Evangelou, Purdue University, West Lafayette}

Demetra Evangelou, Ph.D., is an Assistant Professor in the School of Engineering Education at Purdue University. She obtained her B.A. in psychology from Northeastern Illinois University, and a M.Ed. and Ph.D. in education from University of Illinois, Urbana-Champaign. She is a member of Sigma Xi Science Honor Society. Evangelou was awarded an NSF CAREER grant in 2009 and a Presidential Early Career Award for Scientists and Engineers (PECASE) in 2011. Evangelou's current research focuses on engineering thinking, developmental factors in engineering pedagogy, technological literacy, and humanartifact interactions.

\section{Dr. Johannes Strobel, Purdue University, West Lafayette}

Johannes Strobel is Director of INSPIRE, Institute for P-12 Engineering Research and Learning and Assistant Professor of engineering education and learning design and technology at Purdue University. NSF and several private foundations fund his research. His research and teaching focuses on policy of P-12 engineering, how to support teachers and students' academic achievements through engineering learning, the measurement and support of change of "habits of mind," particularly in regards to sustainability and the use of cyber-infrastructure to sensitively and resourcefully provide access to and support learning of complexity. 


\title{
Troubleshooting Skills for Non-Engineers In Technological Jobs
}

\begin{abstract}
Although there is an increasingly interest for people to become technologically literate, there exists a technical knowledge gap between industry needs and workforce competencies, especially in developing countries such Colombia. That is why technological skills such as troubleshooting need to be developed. Moreover, learning technology skills may be used as a tool for learning new context-specific knowledge.
\end{abstract}

The following study examined why troubleshooting may be an effective tool for non-engineers to learn technical knowledge. Troubleshooting involves essential elements of the learning process. The constant interaction with real artifacts, the immediate feedback and need of reflection for diagnosing faults, and the use of previous knowledge are elements intrinsically integrated to the troubleshooting process.

\section{Introduction}

Technological skills are increasingly required at every level of various organizational structures. In addition to engineers, also technicians and other workers could benefit from having strong technological skills that promote their active involvement in the decision-making process ${ }^{1}$. Especially in developing countries such as Colombia, where is a wide gap between industry requirements and workers knowledge and skills ${ }^{2,3}$, technological skills are crucial. Becoming a technologically literate individual, a person will be able to "use, manage, assess, and understand technology... evaluate the information in [a] story intelligently, put that information in context, and form an opinion based on that information"l. Technology skills such as artifact problem solving are required in the workplace; technicians and other workers need to develop problem solving strategies such as troubleshooting, more than just knowing how a machine works or how to make stocktaking ${ }^{4}$. Moreover, learning those technological skills through work is an effective and practical strategy ${ }^{5}$. Workers can learn through authentic problems ${ }^{6,7}$ and through collaborative learning 8,9 , while are productively engaged in their work.

Constructing and developing technological knowledge, skills and habits of mind helps people to construct new learning ${ }^{10}$. The information can be found in one's experience, in other's knowledge, even in places such as databases, libraries or codes, but if one knows how to transform that information into meaningful knowledge, it does not matter how much information people may gather in order to achieve a specific goal ${ }^{11}$. In fact, if the learner can overcome failure by troubleshooting, which is a particular technological skill, he or she will reduce the time investing in a new task appropriation because they receive immediate feedback ${ }^{4,12}$. 


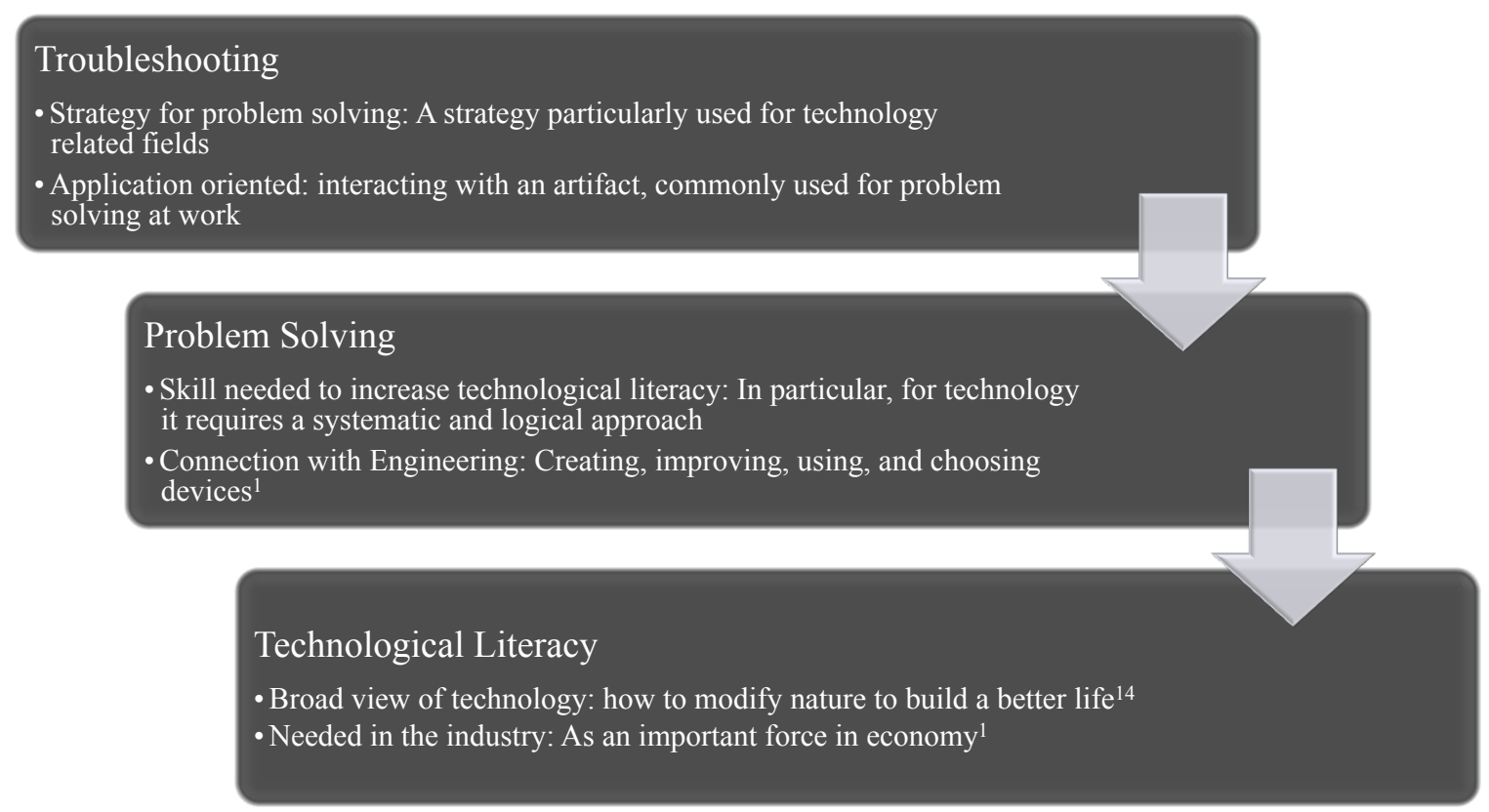

Figure 1

Troubleshooting, as shown in Figure 1, is a strategy for developing problem-solving skills, which are needed to increase technological literacy. Problem-solving skills can be applied to any field or problem; however, the engineering approach to this skill is systematic and analytic. This type of approach is found in troubleshooting processes because it is intrinsically related to technological artifacts, and therefore requires capabilities to create, operate, choose, or improve technology by design and modeling ${ }^{1}$.

Troubleshooting is a complex skill; it involves information management, overcoming failure, and creativity, among others ${ }^{1,13-15}$. Learning process requires the learner be able to get to new information, and deciding which information is useful, relevant, or well grounded, this requires to develop information management skills. Likewise, during training, a person will experiment failure, will commit some errors, but how to overcome these failures determines how the learning process will evolve ${ }^{1,16,17}$. Moreover, the more alternatives the learner find, the more possibilities to overcome failure. Creativity enables the learner to increase the alternatives he or she can find while solving a particular problem ${ }^{9,18,19}$. When using creative thinking, designers create different alternatives for a problem; these alternatives help them to overcome fixation when addressing a problem with its requirements and constrains ${ }^{20-22}$. A creative person can achieve higher troubleshooting skills due to fact that he or she will probably have more than one solution for each problem, having to decide between alternatives. Decision-making, and identifying possible solutions are part of troubleshooting and are needed by technologically literates.

\section{Context for Troubleshooting}

The majority of the studies on troubleshooting mainly illustrate how this technological skill brings benefits to the technology-related industry ${ }^{\text {e.g. } 23,24-32}$. Studies do not use troubleshooting as 
a tool or strategy for learning, but as a goal to learn and apply in future technical work e.g. $26,30,31$. Even in non-technical work the core of the learning is in the learning process for troubleshooting not through troubleshooting ${ }^{33,34}$ : For example in research examining troubleshooting skills of teachers who are integrating technology into the classroom ${ }^{35,36}$ the research does not focus on how troubleshooting is a vehicle to teach technology, but how to deal with technological artifacts in case if a problem occurs, for instance, computer or printing malfunctioning.

\section{Thesis statement}

Little research has analyzed troubleshooting strategies and methods, useful to explain how this skill can be use as a tool for learning ${ }^{30,33,37}$. While previous studies indicate the importance of domain knowledge to perform troubleshooting, we propose that troubleshooting can be used to learn domain knowledge, similarly as a problem is used in problem-based learning as a tool to construct new knowledge ${ }^{6}$. Troubleshooting can be developed through different domains of knowledge, it is transversal to content, and therefore can be used by transferring previous learning into other fields ${ }^{33}$. However, understanding how the system works or understanding the field is needed in order to troubleshoot ${ }^{25,27,33}$.

\section{Using previous knowledge}

Jonassen and Hung ${ }^{33}$ state that there are two types of strategies for troubleshooting: domaingeneral and domain-specific troubleshooting. Beginning troubleshooters tend to use domaingeneral strategies but experienced troubleshooters apply domain-specific ones such as use of previous knowledge of similar systems ${ }^{33,38}$. This difference of the use of previous knowledge is similar as the use of previous knowledge in the learning process ${ }^{39,40}$. When the learners are able to transfer similar problems learned before to new domains they can draw conclusions building in existing cognitive structures, even though the problem maybe new for them ${ }^{38,41}$. The same way, troubleshooters use previous analytical and recursive thinking ${ }^{34}$, they use procedural, strategic, and experiential knowledge in order to solve a new problem ${ }^{33,42}$; they are learning new domain-specific troubleshooting skills and content.

\section{Using artifacts}

One of the elements that makes troubleshooting a learning tool is the constant interaction with artifacts. Some studies suggest that interacting with artifacts can improve the time a person is focused on a specific task ${ }^{43,44}$. Evangelou and colleagues ${ }^{44}$ examine how the direct interaction with artifacts can enhance not only the interaction time, but also the artifact's usage. That is, troubleshooting can provide a positive learning environment because the interaction with the real artifact is intrinsically within the activity. For instance, when a technician is solving a machine problem, if he or she interacts with the machine while making a diagnosis and making decision on what to fix or change, the process will be easier than trying to solve a problem based in just theory for solving a hypothetical problem ${ }^{45}$. Moreover, learners may remain more focused on fixing the problem related to an artifact because of the belief that artifacts were designed for a teleological reason ${ }^{46,47}$. 


\section{Making diagnosis}

The development of some sub-skills within troubleshooting, such as diagnostics, gives the learners an environment for developing analytical, systematic and logical thinking. Authors such as Cash and colleagues ${ }^{4}$ and Johnson ${ }^{26}$ propose that to diagnose is an important skill for troubleshooting. Jonassen and Hung ${ }^{33}$ explain the process of diagnosis by identifying the fault or problem that is preventing the system to work: The diagnose of a fault in a system is the analysis part of the troubleshooting process, where the person has to compile the information gathered in previous steps, to draw a conclusion and in order to make the next action. The diagnosis is the final stage of feedback, because the reflection on the information the system gives to the troubleshooter is used to go a step further.

\section{Using feedback}

Permanent feedback is an equally important element for troubleshooting as for the learning process. Ross and Orr ${ }^{34}$ explain how feedback is important to learn troubleshooting and how feedback is incorporated in a process they call DECSAR as a review of the troubleshooting process $^{34}$. Likewise, other researchers include feedback as an important step in the troubleshooting process ${ }^{19,25-27,29,30,33,37}$. These troubleshooting processes use feedback to make a decision about a possible next step or to correct a previous erroneous action. However, as Hattie and Timperley ${ }^{12}$ explain, feedback can be positive or negative, depending on how it is used. They suggest that praise is not connected with effective learning, but when feedback is constructed from previous learning it can be powerful for the learner.

Taking Hattie's ideas into troubleshooting context help to explain this process as a learning tool. The troubleshooter can receive immediate feedback about their actions because of the outcome of the artifact he or she is fixing. If the action was appropriate, then the artifact's outcome will show a better level of working and the troubleshooter will have information about the action happened and how the effect was achieved. The learner will be able to move forward to the next stage of the troubleshooting process, making further decisions.

Figure 2 shows the four elements of troubleshooting that we have described. Those elements promote an appropriate learning environment for the learning of technology domain knowledge. 


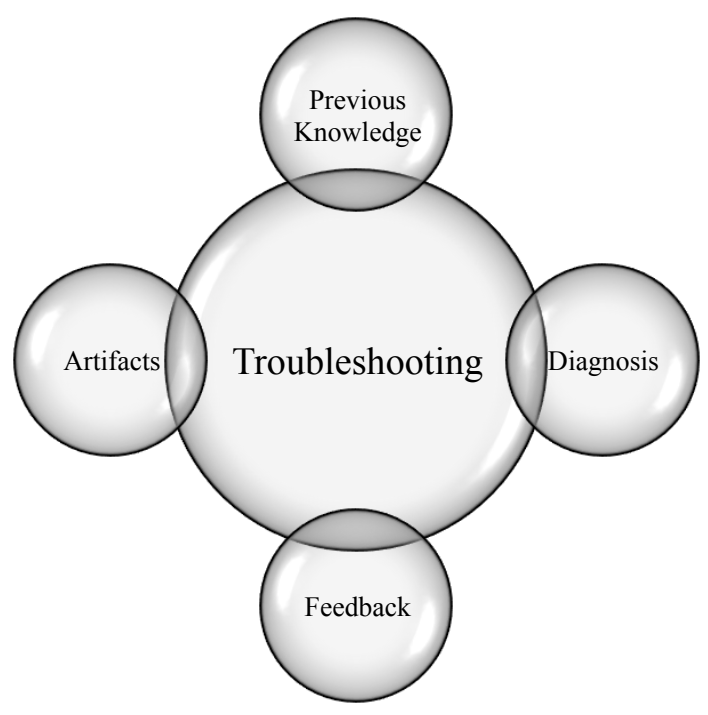

Figure 2

A strategy for the learning of technology domain knowledge

Because of the elements previously examined we suggest that troubleshooting is a good tool for learning; however there is an important final element missing for the learning to occur, the reflection on the troubleshooting activity in order to generalize the process that has been examined. As several researchers state e.g. ${ }^{12,30,33,42}$, the reflection activity is an important part of the learning process. This type of reflection differs from what we previously identified as feedback, because the feedback is immediate, but the reflection during the entire troubleshooting episode requires time to analyze the decision process and to revise how the feedback was received, depending on different decisions. If the troubleshooter does not make a pause to analyze how the last problem differed from others, which new content was needed, or how the problem solving procedure had changed, the learning will be minimal. Similarly if the process was difficult, the learner will remember it better according to Jonassen and Colleagues ${ }^{42,48,49}$. Without reflection interacting with feedback may turn into a trial and error task and not a deliberate action, therefore a troubleshooter might not learn why the goal is achieved. 


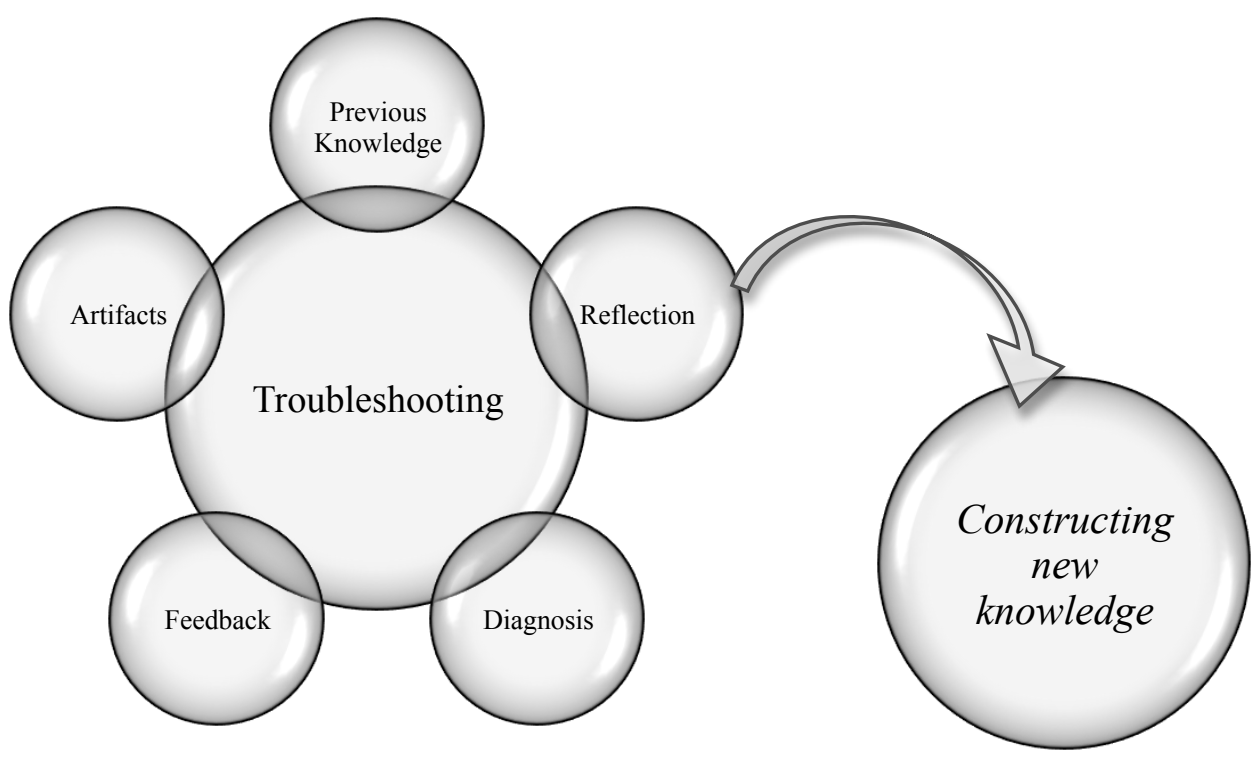

Figure 3

\section{Transferring troubleshooting in order to become technologically literate}

We suggest, using troubleshooting as a learning tool for non-engineer adults, is an effective tool to close the gap of technological literacy between industry needs and workforce capabilities. Thus, some elements of troubleshooting, such as utilization of previous knowledge, immediate feedback with reflection (meta-cognition), constant interaction with an artifact (active process), or relatedness with real life (using work place problems to troubleshoot), may promote transferring knowledge from a situation to other ${ }^{47}$.

The need of previous knowledge in order to diagnose the fault of a system, promotes the transfer of knowledge because diagnosing requires in-depth knowledge and therefore the troubleshooter demands relevant information of the problem. This demand of previous knowledge is engaging novices to inquiry about the specific knowledge domain, while gives to experts the possibility to apply their previous knowledge for diagnosing the fault ${ }^{33,40}$.

The immediate feedback troubleshooting offers to the learner probably supports the transfer process. Feedback allows the learner to reflect on the outcome, and therefore the troubleshooters will try to understand instead of memorize the action or procedure that triggered the particular outcome, and, as Bransford, Brown, and Cocking suggest ${ }^{47}$, higher levels of understanding imply higher levels of transfer.

Feedback in troubleshooting can promote a higher order of thinking in learners and therefore they can use experiences and conclusions in a different problem or artifact to troubleshoot. Interaction with the artifact engages the learner with the task, consequently the amount of time invested for understanding the system and its fault will increase, as well as the learning process $^{47}$. 
Finally, using the workplace, as a learning environment will increase real problem context, hence the motivation will raise $\mathrm{e}^{47,50-52}$ and the learning process will promote transferring learning into new contexts and levels of complexity.

\section{Conclusion}

When a person does troubleshooting, the outputs of the process provide feedback to the troubleshooter, who can reflect about those results and take an action according to his or her decisions. Through the process of fixing a technology artifact, the learner can close the gap in his or her technological literacy. Likewise, the permanent feedback, which occurs during troubleshooting process, maintains a high level of motivation during the task until the goal is achieved.

Using troubleshooting elements such as interaction with an artifact, previous knowledge, feedback, or diagnosing skills can promote a positive learning environment. The constant interaction of a troubleshooter with an artifact may cause an increment of the time invested in the task. Likewise, using previous knowledge lead to connections between experiential knowledge and actual problem. Finally, feedback promotes a constant interaction between troubleshooter's decision and artifact outcomes in order to draw conclusion about the system's faults and therefore developing diagnose skills.

This appropriate learning environment is intrinsically related to technological literacy because of the interaction with the artifact, which is technology itself.

\section{References}

1. International Technology Education Association. Standards for Technological Literacy: Content for the Study of Technology. Third Edition ed. Reston, VA: ITEA; 2007: http://www.iteawww.org/TAA/PDFs/xstnd.pdf.

2. Alcaldia de Funza. Funza: Ciudad Eficiente. Plan de Desarrollo. 2011; www.funza.gov.co/plan.shtml, 2011.

3. Alcaldia de Funza. Acuerdo No.15 Diciembre 07 de 2007. 2011; http://concejodefunza.org/acuerdos/Acuerdos $\% 202007 /$ Acuerdo $\% 20 \mathrm{~N} \%$ BA $\% 20015 \% 20$ Diciembre $\% 200$ $7 \% 20 \mathrm{de} \% 202007$.pdf, 2011.

4. Cash JR, Behrmann MB, Stadt RW. Effectiveness of Cognitive Apprenticeship Instructional Methods in Automotive Technology Classrooms. Journal of Industrial Teacher Education. 1997;34(Winter 1997):2949.

5. Ha TS. How IT Workers Learn in the Workplace. Studies in Continuing Education. July 2008 2008;30(2):129-143.

6. Savery JR, Duffy TM. Problem Based Learning: An Instructional Model and its Constructivist Framework. Bloomington, IN: Indiana University;2001. 
7. Newman M. A Pilot Systematic Review and Meta-Analysis on the Effectiveness of Problem Based Learning. London, UK: Middlesex University;2003.

8. Slavin RE. Cooperative Learning. Review of Educational Research. 1980;50(2):315-342.

9. Howard-Jones PA. Student Perceptions of Collaborative Teaching in Initial Teacher Education and Traning. Journal of the Cardiff School of Education. May 2002 2002;1.

10. Judson E. Improving Technology Literacy: Does it Open Doors to Traditional Content? Education Tech Research Dev. 2010;58:271-284.

11. Siemens G. Connectivism: A Learning Theory for the Digital Age. 2004:1-6.

12. Hattie J, Timperley H. The Power of Feedback. Review of Educational Research. 2007;77(1):81-112.

13. Rugarcia A, Felder RM, Woods DR, Stice JE. The Future of Engineering Education. I. A Vision for a New Century. Chemical Engineering Education. 2000;34(1):16-25.

14. Katehi L, Pearson G, Feder MA, Committee on KEE, National Academy of E, National Research C. Engineering in K-12 education : understanding the status and improving the prospects. Washington, D.C.: National Academies Press; 2009.

15. Committee on Standards for K-12 Engineering Education, National Research Council. Standards for K-12 Engineering Education? Washington, D.C.: The National Academies Press; 2010.

16. National Academy of Engineering. The Engineer of 2020 - Visions of Engineering in the New Century. Washington, D.C: Tha National Academies;2004.

17. National Academy of Engineering. Educating the engineer of 2020 adapting engineering education to the new century. 2005; http://site.ebrary.com/lib/librarytitles/Doc?id=10091305.

18. Dix A, Ormerod T, Twidale M, Sas C, Gomes da Silva PA, McKnight L. Why dab ideas are a good idea. 2006.

19. Abu-Khalaf AM. Improving Thinking Skills in the Unit Operations Laboratory. International Journal of Engineering Education. 2001;17(6):593-599.

20. Chrysikou EG, Weisberg RW. Following the Wrong Footsteps: Fixation Effects of Pictorial Examples in a Design Problem-Solving Task. Journal of Experimental Psychology Learning Memory and Cognition. 2005;31(5):1134-1148.

21. Hatchuel A, Le Masson $P$, Weil B. Teaching innovative design reasoning: How concept- knowledge theory can help overcome fixation effects. Artificial Intelligence for Engineering Design, Analysis and Manufacturing. 2010;25:77-92.

22. Jansson DG, Steven S. Design Fixation. Design Studies. 1991;12(1):3-11.

23. Doherty W. A Partnership ot Provide Teachers With Basic Computer Troubleshooting Skills. Technology and Teacher Education Annual. 2005;4:2573-2576.

24. Doherty W, Gibson K. The Efficacy of Providing Basic Computer Troubleshooting Skills to Pre-Service Teachers. Technology and Teacher Education Annual. 2006;4(2828-2832). 
25. Hale CR, Barsalou LW. Explanation Content and Construction During System Learning and Troubleshooting. The Journal of the Learning Sciences. 1995;4(4):385-436.

26. Johnson D. An Educational Psychology Success Story: Social Interdependence Theory and Cooperative Learning. Educational Researcher. 2009;38(5):365-379.

27. Lee WB, Li JG, Cheung CF. Development of a Virtual Training Workshop in Ultra-Precision Machining. International Journal of Engineering Education. 2002;18(5):584-596.

28. Lesgold A, Lajole S, Bunzo M, Eggan G. Sherlock: A Coached Practice Environment for an Electronics Troubleshooting Job. Pittsburgh, PA: Pittsburgh University;1988.

29. Vasileva T, Furnadziev I, Tchoumatchenko V. Action-Based e-Learning in Electronics. In: Bonk CJ, Lee MM, Reynolds T, eds. World Conference on E-Learning in Corporate, Government, Healthcare, and Higher Education 2008. Las Vegas, Nevada, USA: AACE; 2008:3971-3980.

30. Green DFH. How Refrigeration, Heating, Ventilation, and Air Conditioning Service Technicians Learn From Troubleshooting, Oregon State University; 2006.

31. Johnson D, Johnson R, Smith K. Cooperative Learning Returns To College What Evidence Is There That Is Works? Change: The Magazine of Higher Learning. 1998;30(4):26-35.

32. Lozano-Nieto A. Preparing the Clinical Engineers of the Next Millennium. International Journal of Engineering Education. 1999;15(4):298-307.

33. Jonassen DH, Hung W. Learning to Troubleshoot: A New Theory-Based Design Architecture. Educational Psychology Review. March 2006 2006;18(1):77-114.

34. Ross C, Orr RR. Teaching structured troubleshooting: integrating a standard methodology into an information technology program. Education Tech Research Dev. 2007:251-265.

35. Pope M, Hare D, Howard E. Enhancing Technology Use in Student Teaching: A Case Study. Journal of Technology and Teacher Education. 2005;13(4):573-618.

36. Sandholtz JH. Learning to Teach with Technology: A Comparison of Teacher Development Programs. Journal of Technology and Teacher Education. 2001;9(3):349-374.

37. Vitt JE. Troubleshooting 101: An Instrumental Analysis Experiment. Journal of Chemical Education. December 2008 2008;85(12):1660-1662.

38. Vosniadou S. Conceptual Change and Education. Human Development. 2007;50(1):47-54.

39. Crain W. Theories of Development: Concepts and Applications, Sixth Edition. 6th ed: Pearson Education, Inc., publishing as Prentice Hall; 2011.

40. Bransford J, Brown AL, Cocking RR. How Experts Differ form Novices. How people learn: Brain, mind, experience and school. Washington D.C.: National Academy Press.; 2000:31-50.

41. Chi MTH, Slotta JD, de Leeuw N. From Things to Processes: A Theory of Conceptual Change for Learning Science Concepts. Learning and Instruction. 1994;4:27-43.

42. Jonassen DH, Strobel J, Lee CB. Everyday Problem Solving in Engineering: Lessons for Engineering Educators. Journal of Engineering Education. 2006;95(2):139-151. 
43. Jacobson JL. The Role of Inanimate Objects in Early Peer Interaction. Child Development. June 1981 1981;52(2):618-626.

44. Evangelou D, Dobbs-Oates J, Bagiati A, Liang S, Choi JY. Talking about Artifacts: Preschool Children's Explorations with Sketches, Stories, and Tangible Objects. ECRP. 2010;12.

http://ecrp.uiuc.edu/v12n2/evangelou.html.

45. Conole G. The Role of Mediating Artefacts in Learning Design. The Open University, UK.2008.

46. Kelemen D. Function, Goals and Intention: Children's Teleological Reasoning About Objects. Trends on Cognitive Sciences. December 1999 1999;3(12):461-468.

47. Bransford J, Brown AL, Cocking RR. Learning and Transfer. How people learn: Brain, mind, experience and school. Washington D.C.: National Academy Press.; 2000:51-78.

48. Jonassen DH, Hernandez-Serrano J. Case-Based Reasoning and Instructional Design: Using Stories to Support Problem Solving. Educational Technology, Research and Development. 2002;50(2):65-77.

49. Jonassen DH, Churchill D. Is There a Learning Orientation in Learning Objects? International Journal on E-Learning. April-June 2004 2004;April-June:32-41.

50. Brophy J. Self-determination Theory of Intrinsic Motivation. Motivating Students to Learn. 2 ed. London: Lawrence Erlbaum Assosiates Publishers; 2004:183-219.

51. Csikszentmihalyi M, Abuhamdeh S, Nakamura J. Flow. The Psychology of Optimal Experience 1991:598608 .

52. Dweck CS, Molden DC. Self-Theories. Their Impact on Competence Motivation and Acquisition. Implicit Theories of Ability: Guilford Press; 2005. 